\title{
BARRIERS TO THE ADOPTION OF NEW SAFETY TECHNOLOGIES IN CONSTRUCTION: A DEVELOPING COUNTRY CONTEXT
}

\author{
Jeffrey Boon Hui YAP ${ }^{1 *}$, Canwin Guan Ying LAM®1, \\ Martin SKITMORE(1)2 ${ }^{2}$ Nima TALEBIAN (1)2 \\ ${ }^{1}$ Lee Kong Chian Faculty of Engineering and Science, Universiti Tunku Abdul Rahman (UTAR), \\ Kajang, Malaysia \\ ${ }^{2}$ Faculty of Society and Design, Bond University, Gold Coast, Australia
}

Received 5 August 2021; accepted 20 October 2021

\begin{abstract}
The adoption rate of new technologies is still relatively low in the construction industry, particularly for mitigating occupational safety and health $(\mathrm{OSH})$ risks, which is traditionally a largely labor-intensive activity in developing countries, occupying ill-afforded non-productive management resources. However, understanding why this is the case is a relatively unresearched area in developing countries such as Malaysia. In aiming to help redress this situation, this study explored the major barriers involved, firstly by a detailed literature review to identify the main barriers hampering the adoption of new technologies for safety science and management in construction. Then, a questionnaire survey of Malaysian construction practitioners was used to prioritize these barriers. A factor analysis further identified six major dimensions underlying the barriers, relating to the lack of OSH regulations and legislation, technological limitations, lack of genuine organizational commitment, prohibitive costs, poor safety culture within the construction industry, and privacy and data security concerns. Taken together, the findings provide a valuable reference to assist industry practitioners and researchers regarding the critical barriers to the adoption of new technologies for construction safety management in Malaysia and other similar developing countries, and bridge the identified knowledge gap concerning the dimensionality of the barriers.
\end{abstract}

Keywords: construction industry, safety management, technology adoption, barriers, factor analysis, developing countries.

\section{Introduction}

The construction industry is inherently reluctant to innovate, especially in developing countries (Yap et al., 2019). For example, in investigating industrial revolution (IR) 4.0 in the current Egyptian situation, Alaloul et al. (2020, p. 229) concluded that "the implementation of IR 4.0 within the construction industry is still lacking tremendously despite having the accessibility of these technologies." As Wang et al. (2020, p. 651) highlight, "the implementation of building information modelling (BIM) in many projects has failed to achieve expected benefits due to user resistance." Likewise, in Malaysia, there is a limited utilization of automation and robotics for such on-site construction as structural steelwork and the assembly of prefabricated components (Rohana, 2012). Previous studies found the construction industry in developing countries having a similar pattern of problems despite different geographical, social, political and economic backgrounds (Kang et al., 2018; Yap et al., 2019).
Recently, Forcina and Falcones' (2021) systematic review collected and analyzed 68 articles from 2010 to 2020 to conclude that IR 4.0 enabling technologies can benefit safety management. These enable the smart factory (e.g., cyber-physical system (CPS), radio-frequency identification (RFID), internet of things (IoT), automation, modularization, robotics), simulation and modelling (e.g., building information modelling (BIM), augmented reality $(\mathrm{AV})$, virtual reality (VR), mixed reality (MR)), and digitization and virtualization (e.g., cloud computing, big data, mobile computing) across the entire construction value chain (Oesterreich \& Teuteberg, 2016). However, despite the technological advancements and academic attention in this area, the rate of integrating new technologies into construction safety science and management is still limited (Karakhan et al., 2019). Furthermore, the applications of new technologies for construction safety are mainly a

*Corresponding author. E-mail: bhyap@utar.edu.my

Copyright $\odot 2022$ The Author(s). Published by Vilnius Gediminas Technical University

This is an Open Access article distributed under the terms of the Creative Commons Attribution License (http://creativecommons.org/licenses/by/4.0/), which permits unrestricted use, distribution, and reproduction in any medium, provided the original author and source are credited. 
matter for academic research, with a limited transition into practice (Zhou et al., 2013).

In response, the present study examined the barriers that construction practitioners attribute to inhibiting the application of new technologies to increase construction safety in the context of the developing world; using Malaysia as a base of the study. Notably, little attempt has been made to explore the underlying dimensions of these barriers in the construction domain. As a corollary, therefore, the aim of the study was to contribute towards bridging these gaps in knowledge by providing answers to the research questions:

1. What are the barriers to the adoption of new safety technologies in construction?

2. What are the fundamental underlying dimensions involved?

\section{Literature review}

\subsection{Safety issues in construction}

Construction is also notorious for its poor safety performance when comparing its accident statistics to other industries. Construction sites are famous for their hazardous working conditions and being one of the world's most dangerous working environments in the world (Kang \& Wu, 2020). In Malaysia, the Occupational Safety and Health Department's (DOSH) statistics recorded 169 deaths and 3,911 accidents in 2018 , with a fatality rate of 13.44 per 100,000 workers (Babulal, 2020). This is ten times worse than that of the United Kingdom, for instance, and consistent with Hämäläinen et al. (2006) concerning the disparity of construction safety and health performance between developing and developed countries.

This is partly due to construction sites being dynamic, fast-paced, and risky. The high rate of accidents is also attributed to conventional work processes: these are very labor-intensive with few technological advances, involving unsafe behaviors, use of heavy machinery, and dangerous working conditions (Xu \& Wang, 2020; Zhou et al., 2015). Furthermore, the construction also reported a considerably high incidences of work-related musculoskeletal disorders (WMSDs) among the workers (Rwamamara et al., 2010). For these reasons, construction safety has remained a major issue in both academic research and practice.

\subsection{Advancing safety science with new technologies}

According to Demirkesen and Tezel (2021), the industry's complex and highly dynamic nature demands an acceleration in new technologies to transform the current state of construction safety management. From this perspective, Edirisinghe (2019, p. 184) has emphasized that "the future construction site will be pervasive, context-aware and embedded with intelligence", reinforcing the concept of digital skin for safety objectives.

Indeed, recent years have seen a growing interest in value-creating disruptive innovations to overcome safety problems in the industry and deliver a new competitive advantage. Previous studies investigating a proactive safety management perspective conclude that the utilization of innovative solutions can significantly reduce the workers' exposure to physical safety hazards, which in turn creates a safer work environment (Nnaji \& Karakhan, 2020; Yap et al., 2021; Zhou et al., 2013).

In this regard, innovative solutions can provide safety and operational value on construction sites: safer worksites to better safeguard workers (Oesterreich \& Teuteberg, 2016). For example, safety simulation using information from surveillance cameras is capable of analyzing integrated human-machine-environment risk to provide dynamic safety prewarnings to allow timely corrective actions (Xu \& Wang, 2020). True automation of safety, security, and operational tasks can save time and reduce errors - making worksites run faster, safer, and smarter (Edirisinghe, 2019; Oesterreich \& Teuteberg, 2016; Pan \& Zhang, 2021).

Although there is optimism about the potential for new technologies to help manage project risks, few studies have addressed construction safety problems through the use of new technologies: with the exception of China, this is particularly the case in the context of developing countries (Zhou et al., 2013). Also, the lack of automation and smart systems is linked to poor safety performance (Kamaruddin et al., 2016; Okpala et al., 2020). Zhou's et al. (2015) comprehensive literature review of 439 peerreviewed papers (from 1978 to 2013) published in 10 leading construction management and safety academic journals highlighted six research gaps, one of which concerns the lack of new technology applications in construction safety practice. They further emphasized that most new technology applications remain in the stage of academic research but with limited industrial applications. Furthermore, the potential barriers that could affect the adoption and use of innovative solutions to overcome safety risks still need to be adequately studied and explained (Nnaji \& Karakhan, 2020).

\subsection{Barriers to the adoption of new safety technologies for construction work}

Previous studies make various contributions to the utilization of new technologies for construction safety risk management and the technologies applicable, but studies of the barriers hampering their safety of adoption are quite limited. Given this situation, the review of the literature was extended more broadly to include studies appraising the challenges in adopting such new technologies as IR 4.0, automation, and robotics. This yielded 18 variables/ indicators representing the barriers as summarized in $\mathrm{Ta}$ ble 1 .

Nnaji and Karakhan (2020) have identified 13 key barriers to the adoption of new technologies for OSH management. By prioritizing the survey data collected from 102 construction professionals in several states across the US, the five most critical barriers were found to be "extensive upfront investment required", "need for extensive training before achieving optimum performance", "con- 
Table 1. Summary of barriers to safety technology adoption in construction

\begin{tabular}{|c|c|c|}
\hline No. & Barriers & References \\
\hline A & \multicolumn{2}{|r|}{ Economic-related } \\
\hline A1 & Costly investment associated with new technology & $\begin{array}{l}\text { Aripin et al. (2019), Bademosi and Issa (2021), Delgado et al. (2019), } \\
\text { Kamaruddin et al. (2016), Nnaji and Karakhan (2020), Yahya et al. } \\
\text { (2019) }\end{array}$ \\
\hline $\mathrm{A} 2$ & Required worker training may not be cost effective & $\begin{array}{l}\text { Delgado et al. (2019), Kamaruddin et al. (2016), Nnaji and Karakhan } \\
\text { (2020), Yahya et al. (2019) }\end{array}$ \\
\hline A3 & Slim profit margins in the industry & Loushine et al. (2006), Nnaji and Karakhan (2020) \\
\hline $\mathrm{B}$ & \multicolumn{2}{|r|}{ Regulatory-related } \\
\hline B1 & Lack or no government regulation for use & $\begin{array}{l}\text { Amirah et al. (2013), Nnaji and Karakhan (2020), Pradhananga et al. } \\
(2021)\end{array}$ \\
\hline $\mathrm{B} 2$ & Lack of government commitment & Abdul-Rashid and Abdul-Aziz (2003), Delgado et al. (2019) \\
\hline B3 & Lack of legislation & Abdul-Rashid and Abdul-Aziz (2003), Bademosi and Issa (2021) \\
\hline $\mathrm{C}$ & \multicolumn{2}{|c|}{ Management/leadership-related } \\
\hline $\mathrm{C} 1$ & Lack of top management and leadership support & Cortellazzo et al. (2019), Tam et al. (2001) \\
\hline $\mathrm{C} 2$ & Lack of decision support tools & Nnaji and Karakhan (2020), Pradhananga et al. (2021) \\
\hline $\mathrm{C} 3$ & Creates liability concerns & Bademosi and Issa (2021), Nnaji and Karakhan (2020) \\
\hline $\mathrm{D}$ & \multicolumn{2}{|r|}{ Technical-related } \\
\hline D1 & $\begin{array}{l}\text { Incompatibility of technology with current practices } \\
\text { and current construction operations }\end{array}$ & Bademosi and Issa (2021), Delgado et al. (2019), Yahya et al. (2019) \\
\hline $\mathrm{D} 2$ & $\begin{array}{l}\text { Unavailability of technological assistance for } \\
\text { technology use in the management of OSH }\end{array}$ & Aripin et al. (2019), Kamaruddin et al. (2016) \\
\hline D3 & Technology performance concerns & Delgado et al. (2019), Nnaji et al. (2018), Pradhananga et al. (2021) \\
\hline $\mathrm{E}$ & \multicolumn{2}{|r|}{ Knowledge-related } \\
\hline E1 & Lack of professional knowledge & $\begin{array}{l}\text { Aripin et al. (2019), Kamaruddin et al. (2016), Osunsanmi et al. } \\
(2020)\end{array}$ \\
\hline $\mathrm{F}$ & \multicolumn{2}{|r|}{ Socio-cultural-related } \\
\hline F1 & Culture of the construction industry & Delgado et al. (2019), Rohana (2012) \\
\hline $\mathrm{F} 2$ & Decision to use differs from client requirements & Nnaji et al. (2020b), Shen and Marks (2016) \\
\hline F3 & Ageing workforce resistant to change & $\begin{array}{l}\text { Aripin et al. (2019), Bademosi and Issa (2021), Delgado et al. (2019), } \\
\text { Pradhananga et al. (2021) }\end{array}$ \\
\hline G & \multicolumn{2}{|r|}{ Security-related } \\
\hline G1 & No assurance of data security & $\begin{array}{l}\text { Bademosi and Issa (2021), Gou et al. (2013), Nnaji and Karakhan } \\
\text { (2020), Osunsanmi et al. (2020) }\end{array}$ \\
\hline G2 & Privacy of workers personal data is not guaranteed & Bademosi and Issa (2021), Gou et al. (2013) \\
\hline
\end{tabular}

cerns regarding the technical support availability", "doubts regarding the reliability of these technologies", and "client rarely demands for their use". In South Africa, Osunsanmi et al. (2020) reported the use of RFID with mobile technologies for monitoring construction professionals on site is hindered by their cost and low technical ability.

In another U.S.-based study, the critical factors hindering the broad adoption of robotics in construction were found to include immature technologies, the nature of the industry, complex technical processes involved, economic feasibility, and a weak culture of innovation. In the UK, Delgado et al. (2019) combined the findings from a literature review and qualitative analysis from focus group discussions to reveal a list of 11 limiting factors to robotic adoption in construction. Later, they employed a questionnaire survey for ranking the factors. The three top concerns were high start-up capital, no strong need to increase work efficiency, and low R\&D budgets for innovation capacity. Finally, a factor analysis revealed a 4 -factor solution of relating to contractor-side financial limitations, client-side financial limitations, technical and work culture limitations, and a weak business case. In Malaysia, the main challenges to the adoption of construction robotics are the high cost to acquire, maintain, and update the new technologies (Yahya et al., 2019). In another Malaysian study, Kamaruddin et al. (2016) used a brainstorming workshop to solicit views from experts and experienced practitioners to observe four major barriers of mechanization and automation, which are capital cost, skill resources, maintenance, and availability of the new technologies. According to Rohana (2012), the extent of readiness of the construction industry to utilize construction automation and robotics is related to financial commitments, availability of technical knowledge and equipment, compatibility with 
existing construction practices and operations, situation of the workforce, and characteristics/culture of the industry.

In investigating the common challenges for $I R 4.0$ adoption among U.S.-based construction companies, Demirkesen and Tezel (2021) have reported problems arising from lack of standardization, legal and contractual issues, and cost of implementation. A systematic review by Edirisinghe (2019) noted that the challenges to achieving digital skin at the construction site are primarily associated with technical limitations, problems associated with standardization, haphazard technology design, development, and implementation, with limited studies of the factors that affect the acceptance of new technologies and a lack of understanding of human aspects of technological change.

\section{Methodology}

The quantitative methodology was used, involving a crosssectional structured questionnaire survey adopted to access the barriers to the adoption of new safety technologies in Malaysia's construction industry. Malaysia's Gross National Income (GNI) per capita is at US\$11,200 according to the latest estimates, is classified as a developing nation. The survey method is an effective and economic way of collecting feedback from a relatively large sample in a short time for statistical analysis, as well as being a widely used technique to prioritize relevant variables in construction safety management studies (e.g., Delgado et al., 2019; Nnaji \& Karakhan, 2020; Yap et al., 2020).

Descriptive statistics were obtained, whereby the relative ranking of the barriers was assigned based on the mean scores, considering the views of clients, contractors, and consultants. The Kruskal-Wallis nonparametric analysis of variance (ANOVA) test was used to determine if there were any statistically significant differences between the three respondent groups. A data reduction technique using exploratory factor analysis was then applied to explore the possible underlying factor structure of the identified list of barriers.

\subsection{Questionnaire design}

After identifying the barriers to the adoption of new safety technologies, a questionnaire was developed containing two parts (see Appendix). In Part 1, the participants were asked to provide demographic information about their project role, job position held, years of experience, and academic background. Part 2 provided a list of barriers identified through an integrative literature review (Table 1). For each barrier, the participants were requested to indicate their level of agreement on a five-point Likert scale ranging from 1 (strongly disagree) to 5 (strongly agree).

\subsection{Survey participants and demographics}

The sampling frame consisted of construction professionals familiar with current construction practices in Malaysia, with a tertiary education, and representing the primary parties (client, contractor, and consultant) to obtain industry-wide information. The participants were sampled using convenience and snowball techniques. A total of 600 e-survey forms were distributed by email and the LinkedIn platform. Participation in the survey was voluntary but reminders were made using follow-up emails to increase the response rate. In total, 150 participants responded to the survey. To ascertain the quality of the responses, the researchers checked if there were responses with straightlining and participants not meeting the sampling criteria. Table 2 summarizes the participants' demographic profile with 50 clients, 50 contractors, and 50 consultants. Nearly $70 \%$ are in executive positions, while approximately half have over 5 years of working experience in the construction industry. The participants were regarded as sufficient to exercise sound judgement - establishing the validity of the responses.

Table 2. Demographic profile of respondents

\begin{tabular}{|c|c|c|c|c|c|c|}
\hline \multirow{2}{*}{ Description } & \multirow{2}{*}{ Demography } & \multicolumn{3}{|c|}{ Role in Project } & \multirow{2}{*}{$\mathrm{N}$} & \multirow{2}{*}{$\%$ response } \\
\hline & & Client & Contractor & Consultant & & \\
\hline \multirow[t]{4}{*}{ Job position } & Executive & 35 & 38 & 34 & 107 & 71.3 \\
\hline & Manager & 6 & 4 & 11 & 21 & 14.0 \\
\hline & Senior manager & 8 & 8 & 4 & 20 & 13.3 \\
\hline & Director/top management & 1 & 0 & 1 & 2 & 13.3 \\
\hline \multirow{5}{*}{$\begin{array}{l}\text { Experience working in } \\
\text { construction (years) }\end{array}$} & 5 years or less & 20 & 31 & 27 & 78 & 52.0 \\
\hline & $6-10$ years & 17 & 12 & 12 & 41 & 27.3 \\
\hline & $11-15$ years & 5 & 4 & 6 & 15 & 10.0 \\
\hline & $16-20$ years & 5 & 1 & 2 & 8 & 5.3 \\
\hline & More than 20 years & 3 & 2 & 3 & 8 & 5.3 \\
\hline \multirow{4}{*}{$\begin{array}{l}\text { Highest academic } \\
\text { qualification }\end{array}$} & Diploma & 2 & 1 & 0 & 3 & 2.0 \\
\hline & Bachelor' degree & 38 & 41 & 36 & 115 & 76.7 \\
\hline & Master's degree & 10 & 5 & 11 & 26 & 17.3 \\
\hline & Doctorate/PhD & 0 & 3 & 3 & 6 & 4 \\
\hline
\end{tabular}




\section{Analysis and ranking of barriers}

Cronbach's coefficient $\alpha$ value was 0.895 , which is higher than the threshold of 0.70 needed to establish the internal reliability of the scale used (Hair et al., 2019). Ranked in ascending order based on the overall results, Table 3 presents the means and standard deviations of each barrier according to client, contractor, and consultant type. Overall, all the barriers had a mean score importance rating greater than 3.0, with the five most significant barriers of:

1. Costly investment associated with new technologies (mean $=4.17)$;

2. Culture of the construction industry (mean $=4.01$ );

3. Decision to use differs from the client requirements (mean = 3.79);

4. An ageing workforce resistant to change (mean = 3.70);

5. Lack of top management and leadership support $($ mean $=3.67)$.

For the clients, these are:

1. Costly investment associated with new technologies (mean $=4.04)$;

2. Culture of the construction industry (mean $=4.02$ );

3. An ageing workforce resistant to change (mean $=$ 3.68);

4. Technology performance concerns $($ mean $=3.60)$;

5. Decision to use differs from the client requirements $($ mean $=3.56)$.

For the contractors:

1. Costly investment associated with new technologies $($ mean $=4.04)$;

2. Lack of top management and leadership support $($ mean $=3.80)$;

3. Decision to use differs from the client requirements (mean $=3.74, \sigma=0.853)$;

4. Culture of the construction industry (mean $=3.74$, $\sigma=1.051$ );

5. Availability of technological assistance for the use of new technologies in OSH management (mean = $3.72, \sigma=0.904)$.

For the consultants:

1. Costly investment associated with new technologies (mean $=4.42)$;

2. Culture of the construction industry $($ mean $=4.26)$;

3. Decision to use differs from the client requirements (mean $=4.06)$;

4. Lack of decision support tools (mean $=3.82, \sigma=$ 0.873 );

5. Creation of liability concerns (mean $=3.82, \sigma=$ 1.082).

The highest-ranked barrier of costly investment associated with new technologies is associated with economic feasibility. Adopting new technologies for mechanization and automation means there is a need for a substantial and sustained budget - the capital cost of new technologies and maintenance costs, whereby the equipment is expensive to operate and maintain (Kamaruddin et al.,
2016; Oesterreich \& Teuteberg, 2016). In investigating the readiness of the Malaysian construction industry in utilizing automation and robotics, Rohana (2012) has observed that price sensitivity negatively influences the intention to adopt new technologies. As Aripin et al. (2019) have highlighted, the construction industry is risk-averse to costly investment in new technologies. According to Dodge Data \& Analytics (2019, p. 1), "most contractors don't have a dedicated innovation budget, and tend to pay for new technologies by absorbing the costs in anticipation of long-term gains or by passing on the costs", indicating a half-heartedness in utilizing new technologies to help improve construction safety management. Moreover, the cost of employing new technologies to study human safety can be prohibitive, which poses significant challenges for researchers in this area (You et al., 2018), particularly for prototype building in developing countries. For example, the harsh construction site environment (outdoors, dust, and moisture) involves higher requirements for computing equipment and mobile devices that can withstand the impact from strong vibrations, large falls, and humidity (Oesterreich \& Teuteberg, 2016). In the US, the operation and maintenance costs of new technologies is a major concern among practitioners (Nnaji \& Karakhan, 2020; Dodge Data \& Analytics, 2017). According to Delgado et al. (2019), it is still unclear whether the existing construction market structure and dynamics justifies large capital investments in utilizing new technologies for construction safety risk mitigation.

The persistent fragmentation within the construction industry arises from its multistakeholder and disciplineoriented nature, with the many layers of responsibilities and control within the different phases of construction having a negative influence on project performance, productivity, and the adoption of innovative solutions (Yap et al., 2019). Hence, fragmentation and the project-based nature of activities inhibit technology innovation and adoption across the specialized trades involved (Bademosi \& Issa, 2021; Rohana, 2012) - as a result of confrontational behavior restricting alternative thinking. The unduly fragmented and complex industry dynamics with manual processes across the supply chain creates significant challenges in communication and collaboration, resulting in a strained and adversarial working culture, and inefficiencies related to knowledge hoarding and a lack of coordination (Demirkesen \& Tezel, 2021). Moreover, the extensive use of subcontractors causes many problems in coordination, safety planning, allocating safety responsibility, and communication (Kartam et al., 2000). These characteristics have caused a huge challenge to safety management at construction sites, as well as retarding the diffusion of new safety technologies. The lack of commitment to innovation and inefficient coordination between designers and contractors in terms of promoting new technologies is more likely to make their integration to safety applications more difficult. Against this background, enhancing safety management on smart construction sites will involve future 
construction procurement and project management being more robust and productive, with real-time information retrieval and dissemination, structured and efficient communication, and embedded intelligence (Edirisinghe, 2019).

Clients expect a contractor to finish the work with minimal costs of production (Tam et al., 2001). As Kartam et al. (2000, p. 181) have elucidated, "competitive bidding and owners' negligence in including the cost of safety in tenders all adversely affect the safety performance of many contractors." The current tendering practice that prioritizes "lowest price" is a crucial limitation to innovation (Delgado et al., 2019). Client involvement can significantly influence psychological safety climate (Shen et al., 2015).

Table 3. Mean score and ranking of barriers

\begin{tabular}{|c|c|c|c|c|c|c|c|c|c|c|c|c|c|c|}
\hline \multirow{2}{*}{ Ref. } & \multirow{2}{*}{ Barriers } & \multicolumn{3}{|c|}{ Overall $(\mathrm{N}=150)$} & \multicolumn{3}{|c|}{ Clients $(\mathrm{N}=50)$} & \multicolumn{3}{|c|}{ Contractors $(\mathrm{N}=50)$} & \multicolumn{3}{|c|}{ Consultants $(\mathrm{N}=50)$} & \multirow{2}{*}{$\begin{array}{c}\text { KW } \\
\text { p-value }\end{array}$} \\
\hline & & Mean & SD & Rank & Mean & SD & Rank & Mean & SD & Rank & Mean & $\mathrm{SD}$ & Rank & \\
\hline A1 & $\begin{array}{l}\text { Costly investment } \\
\text { associated with new } \\
\text { technology }\end{array}$ & 4.17 & 0.908 & 1 & 4.04 & 1.009 & 1 & 4.04 & 1.009 & 1 & 4.42 & 0.609 & 1 & 0.132 \\
\hline $\mathrm{F} 1$ & $\begin{array}{l}\text { Culture of the } \\
\text { construction industry }\end{array}$ & 4.01 & 0.952 & 2 & 4.02 & 0.937 & 2 & 3.74 & 0.899 & 4 & 4.26 & 0.965 & 2 & $0.004^{\star *}$ \\
\hline F2 & $\begin{array}{l}\text { Decision to use } \\
\text { differs from client } \\
\text { requirements }\end{array}$ & 3.79 & 0.966 & 3 & 3.56 & 1.181 & 5 & 3.74 & 0.853 & 3 & 4.06 & 0.767 & 3 & 0.087 \\
\hline F3 & $\begin{array}{l}\text { Aging workforce } \\
\text { resistant to change }\end{array}$ & 3.70 & 1.116 & 4 & 3.68 & 1.168 & 3 & 3.72 & 1.051 & 6 & 3.70 & 1.147 & 8 & 0.998 \\
\hline $\mathrm{C} 1$ & $\begin{array}{l}\text { Lack of top } \\
\text { management and } \\
\text { leadership support }\end{array}$ & 3.67 & 1.046 & 5 & 3.46 & 1.182 & 7 & 3.80 & 0.808 & 2 & 3.76 & 1.098 & 7 & 0.306 \\
\hline $\mathrm{C} 2$ & $\begin{array}{l}\text { Lack of decision } \\
\text { support tools }\end{array}$ & 3.65 & 0.969 & 6 & 3.46 & 1.129 & 6 & 3.68 & 0.868 & 7 & 3.82 & 0.873 & 4 & 0.265 \\
\hline $\mathrm{C} 3$ & $\begin{array}{l}\text { Creates liability } \\
\text { concerns }\end{array}$ & 3.62 & 1.014 & 7 & 3.40 & 1.088 & 8 & 3.64 & 0.827 & 9 & 3.82 & 1.082 & 5 & 0.068 \\
\hline D3 & $\begin{array}{l}\text { Technology } \\
\text { performance concerns }\end{array}$ & 3.61 & 0.995 & 8 & 3.60 & 1.069 & 4 & 3.58 & 0.906 & 11 & 3.66 & 1.022 & 11 & 0.806 \\
\hline D2 & $\begin{array}{l}\text { Availability of } \\
\text { technological } \\
\text { assistance for } \\
\text { technology use in the } \\
\text { management of OSH }\end{array}$ & 3.58 & 1.025 & 9 & 3.40 & 1.178 & 9 & 3.72 & 0.904 & 5 & 3.62 & 0.967 & 12 & 0.517 \\
\hline A2 & $\begin{array}{l}\text { Required worker } \\
\text { training may not be } \\
\text { cost effective }\end{array}$ & 3.56 & 1.126 & 10 & 3.24 & 1.271 & 12 & 3.64 & 1.025 & 10 & 3.80 & 1.010 & 6 & 0.058 \\
\hline E1 & $\begin{array}{l}\text { Lack of professional } \\
\text { knowledge }\end{array}$ & 3.51 & 1.219 & 11 & 3.28 & 1.278 & 10 & 3.66 & 1.062 & 8 & 3.60 & 1.294 & 13 & 0.291 \\
\hline D1 & $\begin{array}{l}\text { Incompatibility of } \\
\text { technology with } \\
\text { current practices and } \\
\text { current construction } \\
\text { operations }\end{array}$ & 3.42 & 1.101 & 12 & 3.26 & 1.242 & 11 & 3.58 & 0.906 & 11 & 3.42 & 1.126 & 15 & 0.569 \\
\hline A3 & $\begin{array}{l}\text { Slim profit margins in } \\
\text { the industry }\end{array}$ & 3.41 & 1.050 & 13 & 3.06 & 1.096 & 15 & 3.48 & 0.995 & 12 & 3.68 & 0.978 & 9 & $0.012^{\star}$ \\
\hline G1 & $\begin{array}{l}\text { No assurance of data } \\
\text { security }\end{array}$ & 3.37 & 1.040 & 14 & 3.20 & 1.030 & 13 & 3.46 & 0.930 & 14 & 3.46 & 1.147 & 14 & 0.257 \\
\hline G2 & $\begin{array}{l}\text { Privacy of workers } \\
\text { personal data is not } \\
\text { guaranteed }\end{array}$ & 3.33 & 1.065 & 15 & 3.14 & 0.990 & 14 & 3.44 & 1.033 & 15 & 3.40 & 1.161 & 16 & 0.304 \\
\hline B2 & $\begin{array}{l}\text { Lack of government } \\
\text { commitment }\end{array}$ & 3.24 & 1.163 & 16 & 2.76 & 1.135 & 18 & 3.28 & 1.031 & 17 & 3.68 & 1.151 & 10 & $0.001^{\star *}$ \\
\hline B3 & Lack of legislation & 3.23 & 1.205 & 17 & 2.86 & 1.278 & 17 & 3.48 & 1.054 & 13 & 3.34 & 1.206 & 18 & $0.039^{*}$ \\
\hline $\mathrm{B} 1$ & $\begin{array}{l}\text { Lack or no government } \\
\text { regulation for use }\end{array}$ & 3.19 & 1.151 & 18 & 2.90 & 1.165 & 16 & 3.32 & 1.019 & 16 & 3.36 & 1.225 & 17 & 0.136 \\
\hline
\end{tabular}

Notes: SD denotes standard deviation. KW denotes Kruskal-Wallis. ${ }^{*}$ and ${ }^{* \star}$ denote the mean is significant at the 0.05 and 0.01 level of significance, respectively. 
In this light, the lack of client demand also results in the unwillingness of designers to utilize BIM for safety planning efforts during the design stage (Nnaji \& Karakhan, 2020). As such, client advocacy for the practice of prevention through design $(\mathrm{PtD})$ will drive designers due to the need for improved client relationships and ability to attract new business (Dodge Data \& Analytics, 2017). Given that the client will need to absorb the cost of adopting new technologies for OSH management, limited development budgets and short-term decision making prevent the adoption of new approaches.

Although innovative solutions have great potential for improving productivity, efficiency, and safety through all stages of projects, previous studies highlight the conservative nature of the construction industry, which in turn creates resistance to change (Demirkesen \& Tezel, 2021; Okpala et al., 2019), especially when the change involves a variation in pre-existing methods and re-engineering of basic work processes (Long \& Spurlock, 2008). Technology change resistance may affect the individuals' willingness to accept new technologies and motivation to their use due to uncertainty surrounding the new processes and fear of unknown consequences (Cinite \& Duxbury, 2018). Technology-driven change, such as the use of robotics and automation, may minimize manpower with the possibility of eliminating some construction work (Oesterreich \& Teuteberg, 2016; Okpala et al., 2020). According to Zou (2002, p. 29), "cultural issues involving human behavior, attitudes, thoughts and relationships can lead to resistance to changes in their working environment." New working methods imply that workers have to leave their comfort zone, while many lack the ability to understand their potential increased benefits over traditional work practices (Zou, 2002).

As Yi and Chan (2014, p. 219) have highlighted, "the construction industry has encountered a serious shortage of construction workers, while confronting an ageing workforce and fewer young people entering the construction field". Although some older experienced workers are technophobic (Long \& Spurlock, 2008), safety management in construction is still generally very much reactive. Even the use of simple personal protective equipment (PPE) for safety purposes is still meeting with some resistance by the workers (Teizer et al., 2013). Thus, it is unsurprising that there is a high degree of skepticism in the workforce over the use of such new safety technologies as smart personal wearables (Dodge Data \& Analytics, 2017).

Safety-specific leadership refers to the leaders' endeavors toward safety - leaders creating the organizational climate (Zohar, 2010). The level of safety climate represents the shared perceptions of the safety prioritization compared to other competing priorities (Zohar, 2010). Safety stimuli include policies, procedures, and practices for guiding and directing appropriate and adaptive safety behavior in carrying out task activities (Shen et al., 2015). In this vein, strong safety leadership is a key to improving construction safety, especially for countries where safety is facing significant challenges and requires transformational development (Wu \& Fang, 2017). Thus, top management commitment is needed to support a safety climate to mitigate and prevent hazards and risks in the construction environment (Shen et al., 2015). However, the industry is undermined by several managerial challenges, namely: lack of research and development (R\&D), insufficient safety budgets, insufficient OSH rules, poor safety documentation and procedures, lack of attention from leaders, lack of respect for workers, and inadequate PPE at work (Delgado et al., 2019; Maliha et al., 2021; Yap \& Lee, 2020). Against this background, unsupportive managerial attitudes of the adoption of innovative solutions and a lack of managerial competence in risk assessment have hindered the adoption of new technologies to improve construction safety performance.

The Kruskal-Wallis ANOVA test suggests that only the culture of construction industry (ranked less important by contractors), lack of legislation (ranked more important by contractors), and slim profit margins in the industry and lack of government commitment (both ranked more important by consultants) have statistically significant differences between the three respondent types (Table 3 ).

\section{Exploratory factor analysis}

Exploratory factor analysis is used for analyzing patterns of correlations to uncover underlying factors in the data, and has been widely used as a data reduction technique to group a large number of variables into fewer numbers of factors in previous safety studies in the construction context (e.g., Delgado et al., 2019; Yap \& Lee, 2020). The Kaiser-Meyer-Olkin $(\mathrm{KMO})$ index $(\mathrm{KMO} \geq 0.50)$ and Bartlett's test ( $\mathrm{p}$-value $<0.05$ ) are used to ascertain the factor reliability, whereas the latent root criterion (eigenvalues $>1.0$ ) is applied to determine the optimal number of groupings (Hair et al., 2019). The KMO value of 0.895 and Bartlett's test result ( $\mathrm{p}$-value $=0.000$ ) here indicated the suitability of the data set for factor analysis (see Table 4).

By applying varimax orthogonal rotation, six components were extracted with a cumulative variance of $76.68 \%$, which is greater than the recommended value of $60 \%$ for establishing construct validity (Hair et al., 2019). Each of the variables weighed heavily on only one of the factors, and the loading on each factor exceeded 0.40. The Cronbach's $\alpha$ ranged from 0.710 to 0.906 , indicating that each extracted factor was internally consistent. The label of the underlying factor was assigned according to the variables with higher factor loadings or a whole set of variables (Hair et al., 2019).

\section{Discussion of factor analysis results}

\subsection{Factor 1: Lack of OSH regulations and legislation}

Factor 1 accounted for $15.12 \%$ of the total variance explained, explaining the three most significant barriers concerning government policy and safety-related legislation on $\mathrm{OSH}$ to ensure that construction is safe and well-planned. 
Table 4. Factor analysis results

\begin{tabular}{|c|c|c|c|c|}
\hline Details of the factors and barriers & Factor loading & Variance explained (\%) & Cronbach $\alpha$ & Average mean \\
\hline Factor 1: Lack of OSH regulations and legislation & - & 15.119 & 0.905 & 3.22 \\
\hline Lack of legislation (B3) & 0.874 & & & \\
\hline Lack or no government regulation for use (B1) & 0.842 & & & \\
\hline Lack of government commitment (B2) & 0.800 & & & \\
\hline Factor 2: Technological limitations & - & 14.439 & 0.821 & 3.53 \\
\hline $\begin{array}{l}\text { Unavailability of technological assistance for technology } \\
\text { use in the management of OSH (D2) }\end{array}$ & 0.823 & & & \\
\hline $\begin{array}{l}\text { Incompatibility of technology with current practices and } \\
\text { current construction operations (D1) }\end{array}$ & 0.819 & & & \\
\hline Technology performance concerns (D3) & 0.800 & & & \\
\hline Lack of professional knowledge (E1) & 0.485 & & & \\
\hline Factor 3: Lack of genuine organisational commitment & - & 14.131 & 0.878 & 3.65 \\
\hline Creates liability concerns $(\mathrm{C} 3)$ & 0.823 & & & \\
\hline Lack of decision support tools (C2) & 0.800 & & & \\
\hline Lack of top management and leadership support (C1) & 0.773 & & & \\
\hline Factor 4: Prohibitive costs & - & 11.136 & 0.710 & 3.87 \\
\hline Required worker training may not be cost effective (A2) & 0.848 & & & \\
\hline Slim profit margins in the industry (A3) & 0.741 & & & \\
\hline Costly investment associated with new technology (A1) & 0.622 & & & \\
\hline Factor 5: Safety culture within the construction industry & - & 11.049 & 0.714 & 3.83 \\
\hline Culture of the construction industry $(\mathrm{F} 1)$ & 0.780 & & & \\
\hline Ageing workforce resistant to change (F3) & 0.712 & & & \\
\hline Decision to use differs from client requirements (F2) & 0.704 & & & \\
\hline Factor 6: Privacy and data security concerns & - & 10.810 & 0.906 & 3.35 \\
\hline Privacy of workers personal data is not guaranteed (G2) & 0.919 & & & \\
\hline No assurance of data security (G1) & 0.899 & & & \\
\hline \multicolumn{2}{|c|}{ Cumulative variance explained } & 76.684 & 0.895 & \\
\hline \multicolumn{2}{|c|}{ Kaiser-Meyer-Olkin measure of sampling adequacy } & 0.801 & & \\
\hline \multicolumn{2}{|c|}{ Bartlett's test of sphericity approx. $\chi^{2}$} & 1551.620 & & \\
\hline \multicolumn{2}{|c|}{$\mathrm{df}$} & 153 & & \\
\hline \multicolumn{2}{|r|}{ Sig. } & 0.000 & & \\
\hline
\end{tabular}

Note: Extraction method = Principal component analysis; rotation method = Varimax with Kaiser normalization. Rotation converged in 6 iterations.

Nonetheless, the average mean was the lowest at 3.22, indicating this factor has the least impact on the adoption of new safety technologies for construction. Obsolete safety rules and regulations and their lack of enforcement contributed to high accident rates. For example, the oil and gas industry is engaging "performance-based" safety regulation that is outcome based - requiring a defined outcome but leaving the means of achievement to the regulated entity (Mckinsey Global Institute, 2017). However, non-compliances with OSH regulations are commonplace in construction. Regarding new safety technologies, there is no information relating to standards and government regulations for use, even in the US (Nnaji \& Karakhan, 2020; Okpala et al., 2019). The development of suitable guidelines is needed for their effective adoption for a wide range of construction activities (Pradhananga et al., 2021). Moreover, the lack of government incentives and tariffs to promote the application of new safety technologies has also contributed to their limited use (Delgado et al., 2019).

\subsection{Factor 2: Technological limitations}

This factor encompassed four barriers of technical constraints, accounting for the second-largest variation of $14.44 \%$. Immature technologies and the complex implementation of new technologies are major technical challenges behind their uncertain adoption in construction (Pradhananga et al., 2021). Given that the use of new information and communication technologies (ICT) requires a fast and reliable internet access at construction sites, unreliable broadband connectivity is a significant obstacle to overcome (Oesterreich \& Teuteberg, 2016). Unproved effectiveness highlights the concerns from the industry of the readiness to test new technologies. Additionally, automation is delimited by the highly complicated and interconnected work tasks involved in using robotic and automated systems (Delgado et al., 2019). According to Nnaji et al. (2020a), the application of new safety technologies is influenced by the level of complexity, required features, 
required support, available support, training required, durability, technology effectiveness, reliability, and versatility involved. For example, such issues as interoperability and limitations with sensor devices are common constraints related to BIM and the integration of IoT devices (Tang et al., 2019). Other issues limiting the application of BIM technology include the lack of a standard regulation for the data storage format, lack of a component database, and lack of a standard that can be applied in the process of construction ( $\mathrm{Li}$ et al., 2021). There is a need for strategic technology alliances with high-tech industry for the greater adoption of new technologies (Yahya et al., 2019) to provide safety and operational value.

\subsection{Factor 3: Lack of genuine organizational commitment}

Factor 3 contained three barriers relating to the role of management commitment to safety intervention practices using new technologies. The construction industry has a prevalent weak innovation culture (Pradhananga et al., 2021). The poor safety awareness of firms' top leaders and lack of organizational commitment are major safety risk factors (Jitwasinkul \& Hadikusumo, 2011; Zou \& Zhang, 2009). In transforming the current landscape, all stakeholders need to search for forward-looking solutions when potentially 'game-changing' technologies become available (Mckinsey Global Institute, 2017). In this vein, strong organizational support for change is required (Liu et al., 2016; Wang et al., 2020). Other associated organizational issues include cost savings, peer influence, top management, organizational culture, competitive advantage, and compatibility (Nnaji et al., 2020a).

\subsection{Factor 4: Prohibitive costs}

Factor 4 contains three barriers with a total variance of $11.14 \%$, emphasizing the high costs involved in adopting new construction safety technologies. This factor has the highest average mean of 3.87, indicating the significance of the financial implications of adopting new technologies to streamline construction processes and improve safety performance. In the US, Nnaji and Karakhan (2020) reported that the turnkey cost to adopt new technologies is the topmost barrier to the adoption of new construction safety technologies. Other aspects related to economic feasibility are the true cost of running new technologies, the maintenance required, and immersive training needed to educate and develop skills among workers for a more automated workplace. The cost factors are associated with an initial investment, operating cost, and maintenance cost, which can affect the economic and financial risks borne by organizations (Bademosi \& Issa, 2021). Thus, an extensive costbenefit analysis is needed before the decision to integrate new technologies into construction safety can be made.

\subsection{Factor 5: Construction industry safety culture}

This factor has the second-highest average mean of 3.83. The industry's poor safety record is highly attributable to a poor safety culture both industry-wide and within most organizations (Jitwasinkul \& Hadikusumo, 2011; Zou, 2011); thus, it is unsurprising that the majority of contractors do not earmark a budget for mitigating project risk with predictive analytics (Dodge Data \& Analytics, 2019). The slow adoption of new technologies and an ageing workforce can create inefficiencies and hinder productivity growth (Yap et al., 2019; Yi \& Chan, 2014). A heavy reliance on traditional labor-intensive methods encourages high accident risks, particularly in developing countries. The current work culture of aversion to change highlights the effects of the industry's weak innovation culture (Delgado et al., 2019). For example, the majority of the contractors do not budget for risk mitigation technologies (Dodge Data \& Analytics, 2019). The workforce challenges to the adoption of new technologies are associated with unskilled workers, job security, access to blue-collar workers, and the technology-human interface (Pradhananga et al., 2021), while client demand, competitive advantage, and desire to improve productivity have a low influence on contractors' desire to improve their current safety management practices (Dodge Data \& Analytics, 2017).

\subsection{Factor 6: Privacy and data security concerns}

"Privacy of workers personal data is not guaranteed" (factor loading $=0.919$ ) and "no assurance of data security" (factor loading $=0.899$ ) create this sixth factor, with a total variance of $10.81 \%$, explaining the significance of privacy and security in adopting new technologies to improve work processes and construction safety. Data security and privacy are major issues in IoT (Goyal et al., 2019), where data integrity is not guaranteed (Tang et al., 2019). The automated capture and record of personal data pose some ethical and legal concerns over the tracking and monitoring of workers and handling of the recorded information, which is regulated by the data protection law (Oesterreich \& Teuteberg, 2016). Some privacy policies restrict workers being tagged to track their location and movements, but provide anonymous access location information to restricted or hazardous areas by automatically triggering an alarm (Edirisinghe, 2019). One of the biggest risks associated with the application of unmanned aircraft technology for construction work is regarding privacy concerns (Tatum \& Liu, 2017): sensor-based localization equipment and wearable systems are expensive but can provoke such social issues as privacy, security, legal, and health concerns.

\section{Conclusions}

In recent years, there has been a major upsurge of innovation across various industries, bringing many opportunities for improvements in operational flexibility, efficiency, and safety. However, the construction industry has been lackadaisical in the adoption of technological advancements in comparison with other industries. As reported in previous studies, new technologies certainly have the potential to address some of the inherent challenges of 
conventional construction safety management practices. As Zhou et al. (2013, p. 606) have highlighted, the application of new technologies "is deemed an effective way to further construction safety management." Therefore, the slow uptake of new technologies tends to delay the transformation needed to optimize workplace safety, reduce risks, and improve productivity in the hazardous environments of construction sites. Only limited studies have appraised the challenges to adopting new technologies for safety science and management in construction. To bridge the existing knowledge gap, the present study investigated the barriers to adopting new safety technologies and reveals the underlying dimensionality of the barriers in the Malaysian construction industry.

An extensive review of the literature identified 18 potential major barriers listed in Table 1. This was followed by a questionnaire survey designed and administered to construction practitioners to observe how critical these barriers are perceived according to 50 developers, 50 contractors, and 50 consultants. Overall, the five most significant barriers were found to be the costly investment associated with new technologies, culture of construction industry, decision to use differs from client requirements, ageing workforce is resistant to change, and lack of top management and leadership support. To uncover the underlying barriers, an exploratory factor analysis was conducted, in which six principal factors were manifested, namely: lack of OSH regulations and legislation, technological limitations, lack of genuine organizational commitment, prohibitive costs, safety culture within the construction industry, and privacy and data security concerns.

\section{Implications}

\section{Theoretical implications}

This study provides the theoretical base for the critical barriers to the adoption of new technologies for construction safety according to the cognizance of clients, consultants and contractors; highlighting the several issues in need of immediate attention before effective measures can be devised to better integrate them into construction operations to improve safety performance. The findings from the study suggest a conventionally accepted top-down adoption process and the diffusion of new technologies may not be effective. Of the five most significant barriers, four are related to the social-cultural aspect while one is associated with the economical aspect. Accordingly, building a positive safety culture in construction requires a bottom-up approach, where the people on the ground play a pivotal role in the successful adoption of new safety technologies. Nonetheless, organizations need to increase capital allocation for investing in new technologies that underpin improved safety performance. The identified underlying factors in the context of a developing country are new to construction management literature.

\section{Practical implications}

The adoption of new safety technologies within the construction industry is expected to significantly improve safety performance to be on a par with such counterparts as the manufacturing and automotive industries; at the same time, circumventing the social stigma of being a "dangerous, dirty, and difficult" (3D) industry. However, these barriers identified herewith need to be systematically addressed across the diverse stakeholders involved to ensure successful implementation. The underlying factors largely explain the barriers involved and serve as indicators to guide industry practitioners and policymakers in evaluating the feasibility and state of readiness of adoption technologies for safety management. A shift towards a high-technology and high-skilled construction industry is needed to boost this vital industry for national development in terms of both economy and welfare, and transition a developing economy for growth and higher income.

\section{Limitations and future studies}

A limitation of the study is that the data collected solely using a self-completion questionnaire does not allow further probing to generate further explanation from construction practitioners such as in qualitative interviews. Furthermore, the use of a five-point Likert scale for rating the barriers may not be completely reliable, as different respondents may attach different values to different points of the scale. Although the empirical data were collected in Malaysia, the results might also be relevant for other developing countries where the construction industries share similar characteristics. Future studies investigating other developing countries in Asia and Africa regions will be useful to validate this supposition. Future research opportunities exist to investigate the process-need areas and the enabling factors influencing the adoption of new safety technologies to better align the construction industry toward adopting technology-based safety management systems.

\section{Acknowledgements}

Special gratitude is also extended to those industry practitioners who have kindly participated in the surveys reported in this paper. The authors would also like to thank the anonymous reviewers who have provided constructive comments, which have helped improve the quality of this manuscript. We gratefully acknowledge UTAR Financial Support for Journal Paper Publication scheme.

\section{Funding}

This research was supported by UTAR Research Fund (UTARRF) (Project Number: IPSR/RMC/UTARRF/2021$\mathrm{C} 1 / \mathrm{J} 01)$. 


\section{Author contributions}

All authors have contributions to this article. Conceptualization and supervision, J. B. H. Yap; methodology and formal analysis, C. G. Y. Lam; recourses and data curation, N. Talebian; original draf preparation, M. Skitmore.

\section{Disclosure statement}

No potential conflict of interest was reported by the authors.

\section{References}

Abdul-Rashid, A.-A., \& Abdul-Aziz, H. (2003). Construction safety in Malaysia: A review industry performance and outlook for the future. Journal of Construction Research, 4(2), 141-153. https://doi.org/10.1142/S1609945103000364

Alaloul, W. S., Liew, M. S., Zawawi, N. A. W. A., \& Kennedy, I. B. (2020). Industrial Revolution 4.0 in the construction industry: Challenges and opportunities for stakeholders. Ain Shams Engineering Journal, 11(1), 225-230.

https://doi.org/10.1016/j.asej.2019.08.010

Amirah, N. A., Asma, W. I., Muda, M. S., \& Mohd Amin, W. A. A. W. (2013). Safety culture in combating occupational safety and health problems in the Malaysian manufacturing sectors. Asian Social Science, 9(3), 182-191.

https://doi.org/10.5539/ass.v9n3p182

Aripin, I. D. M., Zawawi, E. M. A., \& Ismail, Z. (2019). Factors influencing the implementation of technologies behind industry 4.0 in the Malaysian construction industry. In International Conference on Built Environment and Engineering 2018 - "Enhancing Construction Industry Through IR4.0" (IConBEE 2018), MATEC Web of Conferences (Vol. 266), Johor, Malaysia, 01006.

https://doi.org/10.1051/matecconf/201926601006

Babulal, V. (2020). Construction related deaths and injuries alarming. New Straits Times. https://www.nst.com.my/news/ nation/2020/02/565830/construction-related-deaths-andinjuries-alarming

Bademosi, F., \& Issa, R. R. A. (2021). Factors influencing adoption and integration of construction robotics and automation technology in the US. Journal of Construction Engineering and Management, 147(8), 04021075.

https://doi.org/10.1061/(ASCE)CO.1943-7862.0002103

Cinite, I., \& Duxbury, L. E. (2018). Measuring the behavioral properties of commitment and resistance to organizational change. Journal of Applied Behavioral Science, 54(2), 113-139. https://doi.org/10.1177/0021886318757997

Cortellazzo, L., Bruni, E., \& Zampieri, R. (2019). The role of leadership in a digitalized world: A review. Frontiers in Psychology, 10. https://doi.org/10.3389/fpsyg.2019.01938

Delgado, J. M. D., Oyedele, L., Ajayi, A., Akanbi, L., Akinade, O., Bilal, M., \& Owolabi, H. (2019). Robotics and automated systems in construction: Understanding industry-specific challenges for adoption. Journal of Building Engineering, 26, 100868. https://doi.org/10.1016/j.jobe.2019.100868

Demirkesen, S., \& Tezel, A. (2021). Investigating major challenges for industry 4.0 adoption among construction companies. Engineering, Construction and Architectural Management. https://doi.org/10.1108/ECAM-12-2020-1059

Dodge Data \& Analytics. (2017). Safety management in the construction industry 2017 (SmartMarket Report). Bedford, MA.
Dodge Data \& Analytics. (2019). Using technology to improve risk management in construction (SmartMarket Insight). Bedford, MA.

Edirisinghe, R. (2019). Digital skin of the construction site: Smart sensor technologies towards the future smart construction site. Engineering, Construction and Architectural Management, 26(2), 184-223. https://doi.org/10.1108/ECAM-04-2017-0066

Forcina, A., \& Falcone, D. (2021). The role of Industry 4.0 enabling technologies for safety management: A systematic literature review. Procedia Computer Science, 180, 436-445. https://doi.org/10.1016/j.procs.2021.01.260

Gou, Q., Yan, L., Liu, Y., \& Li, Y. (2013). Construction and strategies in IoT security system. In 2013 IEEE International Conference on Green Computing and Communications and IEEE Internet of Things and IEEE Cyber, Physical and Social Computing (pp. 1129-1132). IEEE, Beijing, China.

https://doi.org/10.1109/GreenCom-iThings-CPSCom.2013.195

Goyal, P., Sahoo, A. K., \& Sharma, T. K. (2019). Internet of things: Architecture and enabling technologies. Materials Today: Proceedings, 34(3), 719-735.

https://doi.org/10.1016/j.matpr.2020.04.678

Hair, J. F., Black, W. C., Babin, B. J., \& Anderson, R. E. (2019). Multivariate data analysis. Cengage Learning.

Hämäläinen, P., Takala, J., \& Saarela, K. L. (2006). Global estimates of occupational accidents. Safety Science, 44(2), 137156. https://doi.org/10.1016/j.ssci.2005.08.017

Jitwasinkul, B., \& Hadikusumo, B. H. W. (2011). Identification of important organisational factors influencing safety work behaviours in construction projects. Journal of Civil Engineering and Management, 17(4), 520-528.

https://doi.org/10.3846/13923730.2011.604538

Kamaruddin, S. S., Mohammad, M. F., \& Mahbub, R. (2016). Barriers and impact of mechanisation and automation in construction to achieve better quality products. Procedia-Social and Behavioral Sciences, 222, 111-120.

https://doi.org/10.1016/j.sbspro.2016.05.197

Kang, L., \& Wu, C. (2020). Evaluating the safety performance of China's provincial construction industries from 2009 to 2017. Journal of Civil Engineering and Management, 26(5), 435-446. https://doi.org/10.3846/jcem.2020.12646

Kang, Y., Jin, Z., Hyun, C., \& Park, H. (2018). Construction management functions for developing countries: Case of Cambodia. Journal of Management in Engineering, 34(3), 05018004. https://doi.org/10.1061/(ASCE)ME.1943-5479.0000609

Karakhan, A., Xu, Y., Nnaji, C., \& Alsaffar, O. (2019). Technology alternatives for workplace safety risk mitigation in construction: Exploratory study. In T. Hartmann (Ed.), Advances in informatics and computing in civil and construction engineering (pp. 823-829). Cham, Switzerland: Springer International Publishing. https://doi.org/10.1007/978-3-030-00220-6_99

Kartam, N. A., Flood, I., \& Koushki, P. (2000). Construction safety in Kuwait: Issues, procedures, problems, and recommendations. Safety Science, 36(3), 163-184. https://doi.org/10.1016/S0925-7535(00)00041-2

Li, S., Zhang, Z., Mei, G., Lin, D., Yu, J., Qiu, R., Su, X., Lin, X., \& Lou, C. (2021). Utilization of BIM in the construction of a submarine tunnel: A case study in Xiamen City, China. Journal of Civil Engineering and Management, 27(1), 14-26. https://doi.org/10.3846/jcem.2021.14098

Liu, H., Skibniewski, M. J., \& Wang, M. (2016). Identification and hierarchical structure of critical success factors for innovation in construction projects: Chinese perspective. Journal of Civil Engineering and Management, 22(3), 401-416. https://doi.org/10.3846/13923730.2014.975739 
Long, S., \& Spurlock, D. G. (2008). Motivation and stakeholder acceptance in technology-driven change management: Implications for the engineering manager. Engineering Management Journal, 20(2), 30-36. https://doi.org/10.1080/10429247.2008.11431764

Loushine, T. W., Hoonakker, P. L. T., Carayon, P., \& Smith, M. J. (2006). Quality and safety management in construction. Total Quality Management and Business Excellence, 17(9), 1171-1212. https://doi.org/10.1080/14783360600750469

Maliha, M. N., Abu Aisheh, Y. I., Tayeh, B. A., \& Almalki, A. (2021). Safety barriers identification, classification, and ways to improve safety performance in the architecture, engineering, and construction (AEC) industry: Review study. Sustainability, 13(6), 3316. https://doi.org/10.3390/su13063316

Mckinsey Global Institute. (2017). Reinventing construction: A route to higher productivity. Washington, DC, USA.

Nnaji, C., \& Karakhan, A. A. (2020). Technologies for safety and health management in construction: Current use, implementation benefits and limitations, and adoption barriers. Journal of Building Engineering, 29, 101212. https://doi.org/10.1016/j.jobe.2020.101212

Nnaji, C., Lee, H. W., Karakhan, A., \& Gambatese, J. (2018). Developing a decision-making framework to select safety technologies for highway construction. Journal of Construction Engineering and Management, 144(4), 04018016. https://doi.org/10.1061/(ASCE)CO.1943-7862.0001466

Nnaji, C., Gambatese, J., Karakhan, A., \& Osei-Kyei, R. (2020a). Development and application of safety technology adoption decision-making tool. Journal of Construction Engineering and Management, 146(4), 04020028.

https://doi.org/10.1061/(ASCE)CO.1943-7862.0001808

Nnaji, C., Gambatese, J., Lee, H. W., \& Zhang, F. (2020b). Improving construction work zone safety using technology: A systematic review of applicable technologies. Journal of Traffic and Transportation Engineering, 7(1), 61-75.

https://doi.org/10.1016/j.jtte.2019.11.001

Oesterreich, T. D., \& Teuteberg, F. (2016). Understanding the implications of digitisation and automation in the context of Industry 4.0: A triangulation approach and elements of a research agenda for the construction industry. Computers in Industry, 83, 121-139. https://doi.org/10.1016/j.compind.2016.09.006

Okpala, I., Nnaji, C., \& Awolusi, I. (2019). Emerging construction technologies: State of standard and regulation implementation. In ASCE International Conference on Computing in Civil Engineering 2019 (pp. 153-161). ASCE, Atlanta, Georgia. https://doi.org/10.1061/9780784482438.020

Okpala, I., Nnaji, C., \& Karakhan, A. A. (2020). Utilizing emerging technologies for construction safety risk mitigation. Practice Periodical on Structural Design and Construction, 25(2), 04020002.

https://doi.org/10.1061/(ASCE)SC.1943-5576.0000468

Osunsanmi, T. O., Oke, A. E., \& Aigbavboa, C. O. (2020). Barriers for the adoption of incorporating RFID with mobile technology for improved safety of construction professionals. In C. Aigbavbao, \& W. Thwala (Eds), The construction industry in the fourth industrial revolution (pp. 297-304). Cham, Switzerland: Springer International Publishing.

https://doi.org/10.1007/978-3-030-26528-1_29

Pan, Y., \& Zhang, L. (2021). Roles of artificial intelligence in construction engineering and management: A critical review and future trends. Automation in Construction, 122, 103517. https://doi.org/10.1016/j.autcon.2020.103517
Pradhananga, P., ElZomor, M., \& Santi Kasabdji, G. (2021). Identifying the challenges to adopting robotics in the US construction industry. Journal of Construction Engineering and Management, 147(5), 05021003.

https://doi.org/10.1061/(ASCE)CO.1943-7862.0002007

Rohana, M. (2012). Readiness of a developing nation in implementing automation and robotics technologies in construction: A case study of Malaysia. Journal of Civil Engineering and Architecture, 6(7), 858-866.

https://doi.org/10.17265/1934-7359/2012.07.008

Rwamamara, R. A., Lagerqvist, O., Olofsson, T., Johansson, B. M., \& Kaminskas, K. A. (2010). Evidence-based prevention of work-related musculoskeletal injuries in construction industry. Journal of Civil Engineering and Management, 16(4), 499-509. https://doi.org/10.3846/jcem.2010.56

Shen, X., \& Marks, E. (2016). Near-miss information visualization tool in BIM for construction safety. Journal of Construction Engineering and Management, 142(4), 04015100. https://doi.org/10.1061/(ASCE)CO.1943-7862.0001100

Shen, Y., Tuuli, M. M., Xia, B., Koh, T. Y., \& Rowlinson, S. (2015). Toward a model for forming psychological safety climate in construction project management. International Journal of Project Management, 33(1), 223-235.

https://doi.org/10.1016/j.ijproman.2014.04.009

Tam, C. M., Fung, I. W. H., \& Chan, A. P. C. (2001). Study of attitude changes in people after the implementation of a new safety management system: The supervision plan. Construction Management and Economics, 19(4), 393-403.

https://doi.org/10.1080/01446190010027591

Tang, S., Shelden, D. R., Eastman, C. M., Pishdad-Bozorgi, P., \& Gao, X. (2019). A review of building information modeling (BIM) and the internet of things (IoT) devices integration: Present status and future trends. Automation in Construction, 101, 127-139. https://doi.org/10.1016/j.autcon.2019.01.020

Tatum, M. C., \& Liu, J. (2017). Unmanned aircraft system applications in construction. Procedia Engineering, 196, 167-175. https://doi.org/10.1016/j.proeng.2017.07.187

Teizer, J., Cheng, T., \& Fang, Y. (2013). Location tracking and data visualization technology to advance construction ironworkers' education and training in safety and productivity. Automation in Construction, 35, 53-68.

https://doi.org/10.1016/j.autcon.2013.03.004

Wang, G., Wang, P., Cao, D., \& Luo, X. (2020). Predicting behavioural resistance to BIM implementation in construction projects: An empirical study integrating technology acceptance model and equity theory. Journal of Civil Engineering and Management, 26(7), 651-665. https://doi.org/10.3846/jcem.2020.12325

Wu, C., Li, N., \& Fang, D. (2017). Leadership improvement and its impact on workplace safety in construction projects: A conceptual model and action research. International Journal of Project Management, 35(8), 1495-1511.

https://doi.org/10.1016/j.ijproman.2017.08.013

Xu, W., \& Wang, T. K. (2020). Dynamic safety prewarning mechanism of human-machine-environment using computer vision. Engineering, Construction and Architectural Management, 27(8), 1813-1833.

https://doi.org/10.1108/ECAM-12-2019-0732

Yahya, M. Y. Bin, Lee Hui, Y., Yassin, A. B. M., Omar, R., Robin, R. O. A., \& Kasim, N. (2019). The challenges of the implementation of construction robotics technologies in the construction. In International Conference on Built Environment and Engineering 2018 - "Enhancing Construction Industry 
Through IR4.0" (IConBEE 2018), MATEC Web of Conferences, Johor, Malaysia, 05012.

https://doi.org/10.1051/matecconf/201926605012

Yap, J. B. H., \& Lee, W. K. (2020). Analysing the underlying factors affecting safety performance in building construction. Production Planning \& Control, 31(13), 1061-1076. https://doi.org/10.1080/09537287.2019.1695292

Yap, J. B. H., Chow, I. N., \& Shavarebi, K. (2019). Criticality of construction industry problems in developing countries: Analyzing Malaysian projects. Journal of Management in Engineering, 35(5), 04019020.

https://doi.org/10.1061/(ASCE)ME.1943-5479.0000709

Yap, J. B. H., Chong, J. R., Skitmore, M., \& Lee, W. P. (2020). Rework causation that undermines safety performance during production in construction. Journal of Construction Engineering and Management, 146(9), 04020106.

https://doi.org/10.1061/(ASCE)CO.1943-7862.0001902

Yap, J. B. H., Lee, K. P. H., \& Wang, C. (2021). Safety enablers using emerging technologies in construction projects: Empirical study in Malaysia. Journal of Engineering Design and Technology. https://doi.org/10.1108/JEDT-07-2021-0379

Yi, W., \& Chan, A. P. C. (2014). Critical review of labor productivity research in construction journals. Journal of Management in Engineering, 30(2), 214-225.

https://doi.org/10.1061/(ASCE)ME.1943-5479.0000194

You, S., Kim, J. H., Lee, S. H., Kamat, V., \& Robert, L. P. (2018).

Enhancing perceived safety in human-robot collaborative construction using immersive virtual environments. Automation in Construction, 96, 161-170.

https://doi.org/10.1016/j.autcon.2018.09.008

Zhou, Z., Irizarry, J., \& Li, Q. (2013). Applying advanced technology to improve safety management in the construction industry: a literature review. Construction Management and Economics, 31(6), 606-622.

https://doi.org/10.1080/01446193.2013.798423

Zhou, Z., Goh, Y. M., \& Li, Q. (2015). Overview and analysis of safety management studies in the construction industry. Safety Science, 72, 337-350.

https://doi.org/10.1016/j.ssci.2014.10.006

Zohar, D. (2010). Thirty years of safety climate research: Reflections and future directions. Accident Analysis and Prevention, 42(5), 1517-1522. https://doi.org/10.1016/j.aap.2009.12.019

Zou, P. X. W. (2002). Knowledge management practice in two Australian Architecture-Engineering-Construction (AEC) companies. Construction Economics and Building, 4(2), 19-32. https://doi.org/10.5130/AJCEB.v4i2.2928

Zou, P. X. W. (2011). Fostering a strong construction safety culture. Leadership and Management in Engineering, 11(1), 1122. https://doi.org/10.1061/(ASCE)LM.1943-5630.0000093

Zou, P. X. W., \& Zhang, G. (2009). Comparative study on the perception of construction safety risks in China and Australia. Journal of Construction Engineering and Management, 135(7), 620-627.

https://doi.org/10.1061/(ASCE)CO.1943-7862.0000019

\section{APPENDIX}

\section{Questionnaire Form}

This survey will take approximately 5 to 10 minutes to complete. Please be assured that there will be no attempts to disclose your identity throughout this study. All the data will be used purely for academic purpose and will be strictly anonymous. Nevertheless, you may choose to withdraw from this survey at any time if it has made you uncomfortable.

\section{Part I: General Information}

Please tick "ل" in the checkbox.

1. Type of Organization (Please select current type):

$$
\begin{aligned}
& \square \text { Client } \\
& \square \text { Contractor } \\
& \square \text { Consultant }
\end{aligned}
$$

3. Position in the company (Please select one only):

$\square$ Executive
$\square$ Manager
$\square$ Senior manager
$\square$ Director/top management

5. Working experience in construction (Please select one only):

$$
\begin{aligned}
& \square 5 \text { years or less } \\
& \square 6 \text {-10 years } \\
& \square 11-15 \text { years } \\
& \square 16-20 \text { years } \\
& \square \text { More than } 20 \text { years }
\end{aligned}
$$

2. Type of Organization (Please select current type):
Client
Contractor
Consultant

4. Position in the company (Please select one only):
Executive
Manager
$\square$ Senior manager
$\square$ Director/top management

6. Highest academic qualification

(Please select one only):
$\square$ High School
$\square$ Diploma
$\square$ Bachelor's Degree
Master's Degree
Doctorate/PhD 


\section{Part II: Barriers to the adoption of safety technology in construction project}

Please indicate one level of agreement on the following barriers that hinder the adoption of safety technology in construction projects:

\begin{tabular}{|c|c|c|c|c|c|c|}
\hline & Barriers & $\begin{array}{l}\text { Strongly } \\
\text { Disagree }\end{array}$ & Disagree & Neutral & Agree & $\begin{array}{c}\text { Strongly } \\
\text { Agree }\end{array}$ \\
\hline $\mathbf{A}$ & Economic-related & & & & & \\
\hline $\mathrm{A} 1$ & Costly investment associated with new technology & 1 & 2 & 3 & 4 & 5 \\
\hline $\mathrm{A} 2$ & Required workers training may not be cost effective & 1 & 2 & 3 & 4 & 5 \\
\hline A3 & Slim profit margins in the industry & 1 & 2 & 3 & 4 & 5 \\
\hline B & Regulatory-related & & & & & \\
\hline B1 & Lack or no government regulation for use & 1 & 2 & 3 & 4 & 5 \\
\hline B2 & Lack if government commitment & 1 & 2 & 3 & 4 & 5 \\
\hline B3 & Lack of legislation & 1 & 2 & 3 & 4 & 5 \\
\hline $\mathrm{C}$ & Management/leadership-related & & & & & \\
\hline $\mathrm{C} 1$ & Lack of top management and leadership support & 1 & 2 & 3 & 4 & 5 \\
\hline $\mathrm{C} 2$ & Lack of decision support tools & 1 & 2 & 3 & 4 & 5 \\
\hline C3 & Creates liability concerns & 1 & 2 & 3 & 4 & 5 \\
\hline D & Technical-related & & & & & \\
\hline D1 & $\begin{array}{l}\text { Incompatibility of technology with current practices } \\
\text { and current construction operation }\end{array}$ & 1 & 2 & 3 & 4 & 5 \\
\hline D2 & $\begin{array}{l}\text { Availability of technological assistance for technology } \\
\text { use in the management of OSH }\end{array}$ & 1 & 2 & 3 & 4 & 5 \\
\hline D3 & Technology performance concern & 1 & 2 & 3 & 4 & 5 \\
\hline $\mathbf{E}$ & Knowledge-related & & & & & \\
\hline E1 & Lack of professional knowledge & 1 & 2 & 3 & 4 & 5 \\
\hline $\mathbf{F}$ & Socio-cultural-related & & & & & \\
\hline F1 & Culture of construction industry & 1 & 2 & 3 & 4 & 5 \\
\hline F2 & Decision to use differs from client requirements & 1 & 2 & 3 & 4 & 5 \\
\hline F3 & Aging workforce is resistant to change & 1 & 2 & 3 & 4 & 5 \\
\hline G & Security-related & & & & & \\
\hline G1 & No assurance of data security & 1 & 2 & 3 & 4 & 5 \\
\hline G2 & Privacy of workers personal data is not guaranteed & 1 & 2 & 3 & 4 & 5 \\
\hline
\end{tabular}

Thank you for your participation. Your response is of high importance for this study and is much appreciated. 